\title{
Effects of exercise training on gut hormone levels after a single bout of exercise in middle-aged Japanese women
}

Shin-ya Ueda ${ }^{*}$, Tadayoshi Miyamoto ${ }^{1}$, Hidehiro Nakahara' ${ }^{1}$, Toshiaki Shishido ${ }^{2}$, Tatsuya Usui ${ }^{3}$, Yoshihiro Katsura ${ }^{4}$, Takahiro Yoshikawa ${ }^{5}$ and Shigeo Fujimoto ${ }^{5}$

\begin{abstract}
The purpose of this study was to investigate the effects of 12 weeks of exercise training on gut hormone levels after a single bout of exercise in middle-aged Japanese women. Twenty healthy middle-aged women were recruited for this study. Several measurements were performed pre and post exercise training, including: body weight and composition, peak oxygen consumption (peak $\mathrm{VO}_{2}$ ), energy intake after the single bout of exercise, and the release of gut hormones with fasting and after the single bout of exercise. Exercise training resulted in significant increases in acylated ghrelin fasting levels (from $126.6 \pm 5.6$ to $135.9 \pm 5.4 \mathrm{pmol} / \mathrm{l}, P<0.01$ ), with no significant changes in GLP-1 (from $0.54 \pm 0.04$ to $0.55 \pm 0.03 \mathrm{pmol} / \mathrm{ml}$ ) and PYY (from $1.20 \pm 0.07$ to $1.23 \pm 0.06$ $\mathrm{pmol} / \mathrm{ml}$ ) fasting levels. GLP-1 levels post exercise training after the single bout of exercise were significantly higher than those pre exercise training (areas under the curve (AUC); from $238.4 \pm 65.2$ to $286.5 \pm 51.2 \mathrm{pmol} / \mathrm{ml} \times 120 \mathrm{~min}$, $P<0.001$ ). There was a tendency for higher AUC for the time courses of PYY post exercise training than for those pre exercise training (AUC; from $519.5 \pm 135.5$ to $551.4 \pm 128.7 \mathrm{pmol} / \mathrm{ml} \times 120 \mathrm{~min}, P=0.06$ ). Changes in (delta) GLP-1 AUC were significantly correlated with decreases in body weight $(r=-0.743, P<0.001)$, body mass index $(r=-0.732, P<0.001)$, percent body fat $(r=-0.731, P<0.001)$, and energy intake after a single bout exercise $(r=-0.649, P<0.01)$ and increases in peak $\mathrm{VO}_{2}(r=0.558, P<0.05)$. These results suggest that the ability of exercise training to create a negative energy balance relies not only directly on its impact on energy expenditure, but also indirectly on its potential to modulate energy intake.
\end{abstract}

Keywords: Glucagon-like peptide-1, Peptide YY, Ghrelin, Exercise training

\section{Introduction}

The role of gut hormones in the treatment of obesity has been widely recognized (Derosa and Maffioli 2012; Field et al. 2009; Karra and Batterham 2010; Neary and Batterham 2009). Glucagon-like peptide-1 (GLP-1) is a satiety factor (Barrera et al. 2011; Gallwitz 2012; Torekov et al. 2011), which is released into the circulation after a meal in proportion to the amount of food consumed, and the major source of postprandial GLP-1 release is Lcells of the intestine (Barrera et al. 2011; Gallwitz 2012; Torekov et al. 2011). In addition, GLP-1 is the most powerful known incretin in humans, and manipulation

\footnotetext{
* Correspondence: s-ueda@morinomiya-u.ac.jp

'Department of Acupuncture, Morinomiya University of Medical Sciences,

1-26-16, Nankokita, Suminoe-ku, Osaka City, Osaka 559-8611, Japan Full list of author information is available at the end of the article
}

of the GLP-1 system forms the basis of several major new treatments for type 2 diabetes (Barrera et al. 2011; Gallwitz 2012; Torekov et al. 2011). Peptide YY (PYY) is also recognized as a satiety factor, and is secreted from L-cells of the intestine after a meal and suppressed by fasting (Nguyen et al. 2011; Ueno et al. 2008). On the other hand, ghrelin is the only orexigenic endogenous hormone, and is secreted from the stomach due to fasting (Schellekens et al. 2012).

Interestingly, previous studies have revealed the inhibitory effects of acute exercise on the hunger associated with these hormones in healthy subjects (Broom et al. 2009; Cheng et al. 2009; Martins et al. 2007). We also demonstrated that a single bout of aerobic exercise caused significant increases in the plasma levels of GLP1 and PYY, and decreases in subsequent energy intake in 
obese and non-obese subjects (Ueda et al. 2009a, b). Furthermore, increases in GLP-1 levels during exercise were significantly and negatively correlated with decreases in the amount of energy ingested (Ueda et al. 2009a). These findings suggest the intriguing possibility that exercise may partly function as a physiological regulator for hormone release or metabolism and thus lead to appetite control.

Previous training studies have examined changes in fasting hormone responses before and after an exercise training intervention, but not acute exercise (Jones et al. 2009; Kelly et al. 2009; Martins et al. 2010; Roth et al. 2005). To our knowledge, however, none have further examined if hormonal responses are altered after a single exercise bout. Clear understanding of the changes in gut hormones after a single bout of exercise by exercise training may potentially help us to develop new exercise programs for the prevention and treatment of obesity.

Therefore, the purpose of this study was to investigate the effects of 12 weeks of exercise training on gut hormone levels after a single bout of exercise in middle-aged Japanese women and to determine whether any changes correlated with the magnitude of exercise traininginduced changes in body composition, fitness levels, and energy intake after the single bout of exercise.

\section{Methods}

\section{Subjects}

Twenty-eight healthy middle-aged women were recruited for this protocol. All subjects were lifelong nonsmokers with a sedentary to moderately active lifestyle (less than one hour of intense exercise per day), and reported stable weight and lack of any special type of diet for the previous 6 months. None had any history of infectious disease for at least the 1-month period preceding the study, and none were taking medication. Subjects with a history of gastrointestinal, endocrine, cardiovascular, or psychological disease or type- 1 or type-2 diabetes were excluded. Eight subjects were excluded due to trouble in home $(n=3)$, falls out of the training time $(n=4)$, and infectious disease $(n=1)$. Finally twenty subjects (mean \pm SEM. $49.1 \pm 0.8$ years) were recruited for this study. Subject characteristics are shown in Table 1. All subjects provided written informed consent for participation in the study, which was approved by the Ethics Committee of Morinomiya University of Medical Sciences (Admitting No. 2012-002).

\section{Study protocol}

Several measurements were performed before and after 12 weeks of exercise training, including: body weight and composition, peak oxygen consumption (peak $\mathrm{VO}_{2}$ ), energy intake after the single bout of exercise, the release of gut hormones with fasting and after the single bout of exercise, glucose, insulin, and feelings of hunger and satiety.

\section{Exercise program}

The aerobic exercise training was $80 \mathrm{~min}$, three times per week for 12 weeks. Aerobic exercise was led by two trained fitness instructors and supervised by researchers. The training protocol consisted of 80 min with 10-min warmup and flexibility exercise, 60-min aerobic exercise based on jogging (AR100, Minato Medical Science Inc., Tokyo, Japan) and cycling (Excalibur v2.0, Lode, Groningen, Netherlands), and a 10-min cool-down. The intensity of the aerobic exercise was approximately $65 \%$ of their maximal heart rate.

\section{Body composition}

Body composition was measured by the extremities induction twelve-electrode bioelectrical impedance method (MC190, Tanita Corporation, Tokyo, Japan).

\section{Peak $\mathrm{VO}_{2}$ measurement}

Subjects performed a cycle ergometer (Excalibur v2.0, Lode, Groningen, Netherlands) ramp exercise test $(20 \mathrm{~W} / \mathrm{min})$ to determine peak $\mathrm{VO}_{2}$ after 3 min rest on the ergometer and a 3 min $0 \mathrm{~W}$ warm-up as previously described (Ueda et al. 2009a, b). Peak $\mathrm{VO}_{2}$ was measured with an AE-310S Aeromonitor (Minato Medical Science Inc., Tokyo, Japan). Ventilatory and $\mathrm{O}_{2}$ consumption variables were calculated using the breath-by -breath method. The electrocardiogram and heart rate were continuously monitored using Dyna-Scope (DS3140, Fukuda Densi, Tokyo, Japan) throughout the ramp exercise test. Perceived exertion was rated every minute with the Borg scale (Borg 1973). Attainment of peak

Table 1 Subject characteristics

\begin{tabular}{|c|c|c|c|}
\hline & Pre & Post & Significance \\
\hline Weight (kg) & $68.0 \pm 1.1$ & $65.8 \pm 1.0$ & $* * *$ \\
\hline Body mass index $\left(\mathrm{kg} / \mathrm{m}^{2}\right)$ & $27.6 \pm 0.4$ & $26.8 \pm 0.4$ & $* * *$ \\
\hline Body fat (\%) & $31.0 \pm 0.8$ & $28.6 \pm 0.8$ & $* * *$ \\
\hline Peak $\mathrm{VO}_{2}(\mathrm{ml} / \mathrm{kg} / \mathrm{min})$ & $23.5 \pm 0.9$ & $28.1 \pm 0.8$ & $* * *$ \\
\hline Energy intake after the single bout of exercise (kcal) & $835.6 \pm 36.8$ & $808.5 \pm 41.8$ & NS $(P=0.08)$ \\
\hline
\end{tabular}

All values are described as mean \pm SEM. ${ }^{* * *} P<0.001$ : pre versus post exercise training. 
$\mathrm{VO}_{2}$ was validated if two of the following four criteria were satisfied: (1) an oxygen uptake plateau despite increasing exercise intensity ( $\leqq 150 \mathrm{ml} / \mathrm{min}$ ); (2) a respiratory exchange ratio $\geqq 1.10$; (3) a maximal heart rate within 10 beats / min of the age-predicted maximal value; and (4) a Borg scale $=$ of 10 (Borg 1973).

\section{Blood sampling and measures of appetite}

To control the subject's physical activity on the days prior to, and on the mornings of, the experiment, subjects were instructed to refrain from moderate to heavy exercise for at least 24 hours prior to each investigation. The design of the experimental session is shown diagrammatically in Figure 1. Subjects received a standard evening meal (instant noodles and a piece of cheese: $532 \mathrm{kcal}, 13.9 \%$ protein, $26.6 \%$ fat, and $59.5 \%$ carbohydrate) at around $2100 \mathrm{~h}$ on the day preceding each study day. Subjects came to the laboratory at $0930 \mathrm{~h}$ and, after a 10 min rest period, a cannula was inserted into the antecubital vein and a fasting venous blood sample (baseline) was taken $(20 \mathrm{ml})$. A standard breakfast (biscuits, yogurt, and jelly: $560 \mathrm{kcal}, 16.5 \%$ protein, 19.3\% fat, and $64.2 \%$ carbohydrates) was then served at $0950 \mathrm{~h}$ and participants remained seated quietly. At $1100 \mathrm{~h}(t=$ $0 \mathrm{~min}$ ), the subject exercised on the cycle ergometer at $50 \%$ peak $\mathrm{VO}_{2}$ for $30 \mathrm{~min}$. During these sessions and after the end of the exercise $(t=0,30,60 \mathrm{~min})$, blood samples were collected. In addition, ratings of subjective feelings of hunger and satiety were reported on a $100 \mathrm{~mm}$ visual analogue scale (VAS) during the study period ( $t=$ baseline, 0, 30, $60 \mathrm{~min}$ ) (Flint et al. 2000).
Measurement of energy intake after a single bout of exercise At $1200 \mathrm{~h}(t=60 \mathrm{~min})$, a test meal (instant pasta: 7.9\% protein, $44.6 \%$ fat, and $47.5 \%$ carbohydrates (energy percent)) was provided and subjects were instructed to eat as much as they liked until satisfied, as described previously (Ueda et al. 2009a, b). In order to exclude the possibility that the amount of food eaten depended on its palatability, we asked all subjects which foods they liked prior to the study, and selected instant pasta as the test meal. We filled a small bowl with the test pasta and repeatedly filled the bowl with pasta before the participant had emptied it to ensure blindness to the amount of food eaten. No time limit was set for eating under either experimental condition. During the sessions, subjects and experimenters were instructed to abstain from talking about the meal. Participants were not overly informed that the true purpose of the present study was to assess feeding responses where possible until they had completed the protocol. After consumption of the test meal, any remaining food was weighed, and the amount determined was subtracted from the premeal value to obtain the total amount of food ingested. Absolute energy intakes from the test meal in both sessions (before and after the 12week exercise training program) were then calculated from the amount of food eaten $(1.15 \mathrm{kcal} / \mathrm{g})$.

\section{Gut hormones, glucose, insulin, and hematocrit} measurements

Blood samples were immediately transferred into disodium EDTA-treated tubes for measuring plasma glucose and hormones. In addition, aprotinin, a potent protease

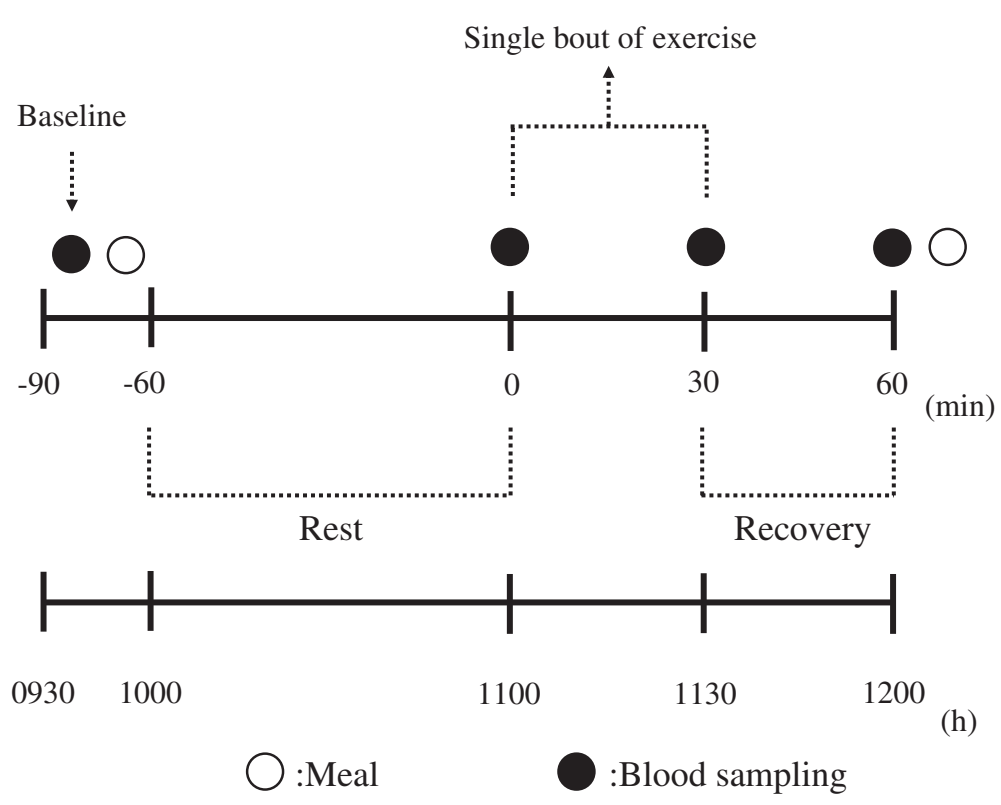

Figure 1 Scheme of the experimental session. 
inhibitor, was added to samples at a concentration of 500 $\mathrm{kIU} / \mathrm{ml}$ for the measurement of ghrelin. Test tubes were then centrifuged (KUBOTA 2010, KUBOTA Corporation, Tokyo, Japan) at 3000 r.p.m. for $15 \mathrm{~min}$ at $4^{\circ} \mathrm{C}$ immediately after collection, and plasma samples were stored at $-80^{\circ} \mathrm{C}$ until used for hormone assays. Insulin was determined by the fully automated chemiluminescence method (CLIA). Glucose was measured using the enzymatic reference method with hexokinase. Plasma GLP-1 (GLP-1 (7-36) amide) and PYY levels were determined by EIA (Human GLP-1/PYY EIA kit, Yanaihara Institute Inc., Shizuoka, Japan). The ELISA for PYY quantified the total amount of both $\mathrm{PYY}_{1-36}$ and $\mathrm{PYY}_{3-36}$. Plasma acylated ghrelin levels were assessed by ELISA (Active Ghrelin ELISA kit, Mitsubishi Kagaku Iatron Inc., Tokyo, Japan). The interassay coefficients of variation for GLP-1, PYY, and ghrelin were each less than $18 \%$. The sensitivities (minimum limits of detection) of GLP-1, PYY, and ghrelin were $0.062,0.03$, and $2.5 \mathrm{pmol} / \mathrm{l}$, respectively. All sample measurements were performed in duplicate according to the manufacturers' instructions. Hematocrit was measured using a Celltac alpha (Nihon Kohden Inc., Tokyo, Japan).

\section{Statistical analyses}

All statistical analyses were performed using SPSS for Windows (SPSS Inc., Chicago, IL, USA). All data were normally distributed, assessed by the Kolmogorov-Smirnov test, and presented as means \pm SE. Exercise training effects on each variable were tested by the Student's paired $t$-test. In addition, to examine the effects of exercise training and time on the levels of hematocrit, glucose, insulin, gut hormones, and VAS scores, a two-way analysis of variance (ANOVA) with repeated measures was performed. If significance was detected, post-hoc multiple pair-wise comparisons (Tukey-Kramer test) were performed.

Areas under the curve (AUC) were calculated using the trapezoidal rule to assess total changes in each gut hormone, insulin, and glucose during each session (baseline to $t=60$ ). The effects of exercise training on the AUC of each gut hormone, insulin, and glucose were assessed using the Student's paired $t$-test. In addition, correlations between changes in the AUC of each gut hormone and other parameters were determined by simple correlation using Pearson's correlation coefficient and stepwise multiple regression. Stepwise regression analysis was performed for other parameters as independent variables and the AUC of each gut hormone as a dependent variable. $P$-values less than 0.05 were considered significant.

\section{Results}

Changes in anthropometry, body composition, fitness levels, and energy intake after the single bout of exercise are shown in Table 1. There was a significant reduction in body weight $(P<0.001)$, BMI $(P<0.001)$, and percentage body fat $(P<0.001)$ and a significant increase in peak $\mathrm{VO}_{2}(P<0.001)$ after exercise training. Despite a tendency for lower energy intake after the single bout of exercise after exercise training, no significant changes were seen $(P=0.08)$.

\section{Fasting blood parameters}

Changes in fasting glucose, insulin, and gut hormones are shown in Table 2. Exercise training resulted in a significant reduction in insulin $(P<0.001)$ and increase in ghrelin fasting levels $(P<0.01)$, but significant changes were not seen for glucose, GLP-1, and PYY fasting levels.

\section{Blood parameters and feelings of hunger and satiety after the single bout of exercise}

Significant changes in hematocrit were not observed over time during exercise. Hemoconcentration was thus unlikely to have occurred during the exercise sessions performed in the present study (data not shown). No significant differences in the levels of glucose and insulin were observed between pre and post exercise training throughout the course of observation (data not shown). Figure 2 shows the time courses of GLP-1 levels. A significant main effect of exercise training $(P<0.001)$, time $(P<0.001)$, and interaction $(P<0.001)$ were observed on GLP-1 levels. GLP-1 levels post exercise training after the single bout of exercise were significantly higher than those of pre exercise training (post-hoc test: $P<0.001$, at $t=30$ and $60 \mathrm{~min}$ ). In addition, mean AUC values for GLP-1 post exercise training were significantly higher than those of pre exercise training $(P<0.001)$. Figure 3 shows the time courses of PYY levels. A significant main effect of time $(P<0.001)$, but no effect of exercise training or interaction, was observed on PYY levels. However, there was a tendency for higher mean AUC values for PYY post exercise training than those of pre exercise training $(P=0.06)$. Figure 4 shows the time courses of acylated ghrelin levels. A significant main effect of time $(P<0.001)$, but no effect of exercise training or interaction, was observed on active ghrelin levels. In addition, mean AUC values for active ghrelin did not change with

Table 2 Fasting glucose, insulin, and gut hormones

\begin{tabular}{llll}
\hline & Pre & Post & Significance \\
\hline Glucose $(\mathrm{mg} / \mathrm{dl})$ & $90.3 \pm 2.5$ & $89.6 \pm 2.4$ & NS \\
Insulin $(\mu \mathrm{U} / \mathrm{ml})$ & $11.8 \pm 0.7$ & $9.4 \pm 0.5$ & $* * *$ \\
GLP-1 $(\mathrm{pmol} / \mathrm{ml})$ & $0.54 \pm 0.04$ & $0.55 \pm 0.03$ & NS \\
PYY $(\mathrm{pmol} / \mathrm{ml})$ & $1.20 \pm 0.07$ & $1.23 \pm 0.06$ & NS \\
Ghrelin $(\mathrm{pmol} / \mathrm{l})$ & $126.6 \pm 5.6$ & $135.9 \pm 5.4$ & $* *$ \\
\hline
\end{tabular}

All values are described as mean \pm SEM. ${ }^{* * *} P<0.001,{ }^{* *} P<0.01$ : pre versus post exercise training. 

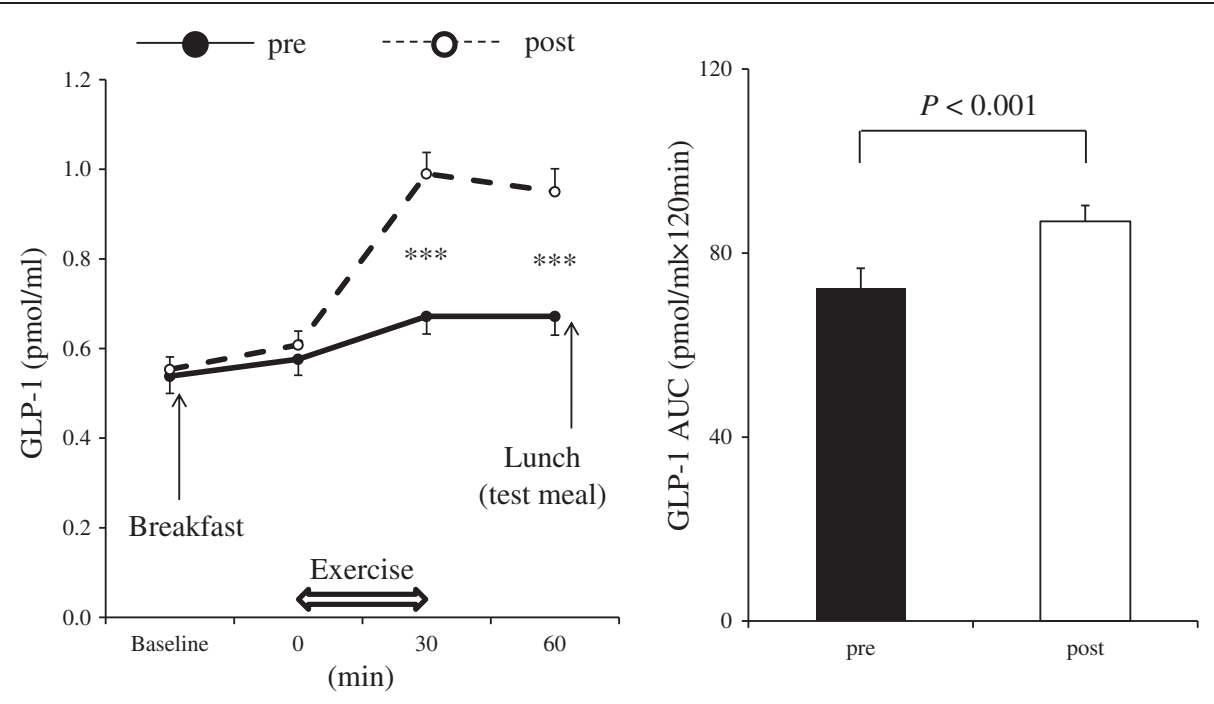

Figure 2 Plasma level responses of GLP-1 to a single bout of exercise (left) and area under the curve values for GLP-1 (right). Mean values \pm SEM of each parameter are presented. Two-way ANOVA for repeated measures (left): Main effect of exercise training, $P<0.001$; main effect of time, $P<0.001$; interaction effect of exercise training $\times$ time, $P<0.001 .{ }^{* * *} P<0.001$, pre versus post exercise training.

exercise training. No significant differences in hunger, fullness, satiety, or motivation to eat were observed between pre and post exercise training throughout the course of observation (data not shown).

\section{Correlations of changes in gut hormone levels and each measurement parameter}

Changes in (delta) GLP-1 AUC were significantly correlated with decreases in body weight $(r=-0.743, P<0.001)$, BMI $(r=-0.732, P<0.001)$, percent body fat $(r=-0.731$,
$P<0.001)$, and energy intake after the single bout of exercise $(r=-0.649, P<0.01)$ and increases in peak $\mathrm{VO}_{2}$ $(r=0.558, P<0.05)$ (Table 3$)$. In contrast, no significant correlations between the delta of AUC values for PYY and ghrelin levels and changes in each measurement parameter were observed (data not shown). To investigate which variables accounted for these associations with AUC of each gut hormone, stepwise multiple regression analysis was performed. Consequently, body weight $\left(\mathrm{r}^{2}=0.552\right.$, $P<0.01)$, BMI $\left(r^{2}=0.536, P<0.01\right)$, and percent body fat
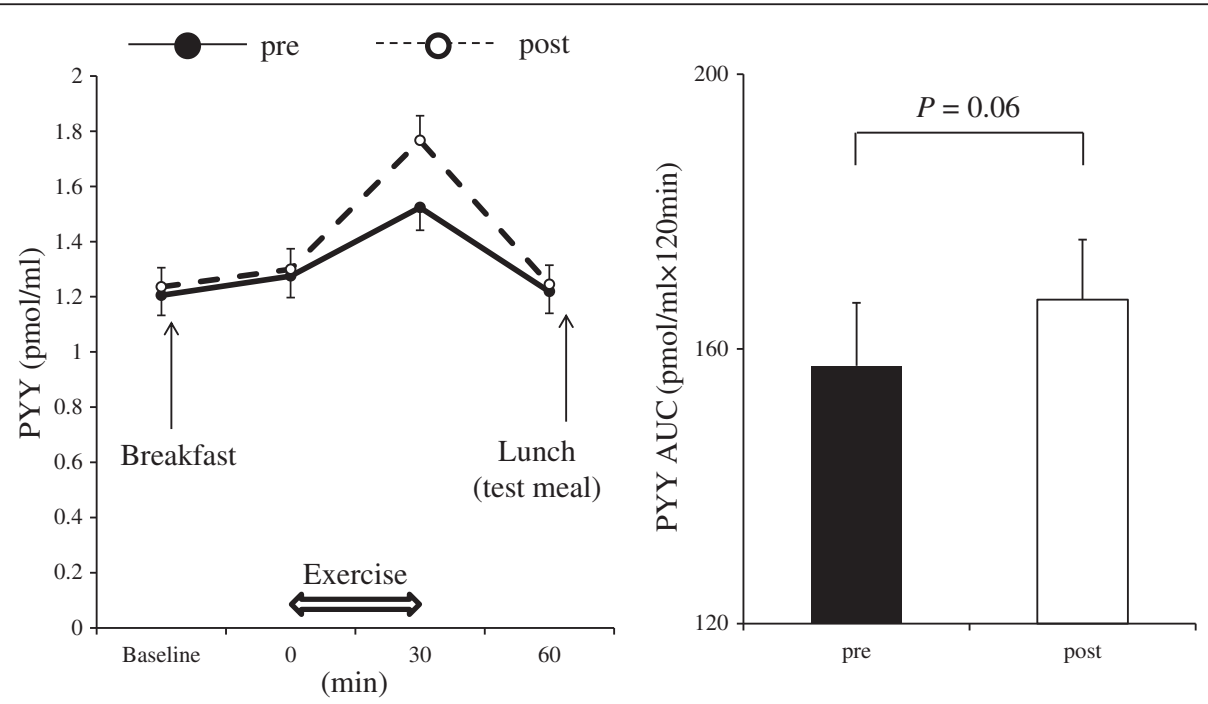

Figure 3 Plasma level responses of PYY to a single bout of exercise (left) and area under the curve values for PYY (right). Mean values \pm SEM of each parameter are presented. Two-way ANOVA for repeated measures (left): Main effect of exercise training, $P=0.14$; main effect of time, $P<0.001$; interaction effect of exercise training $\times$ time, $P=0.40$. 

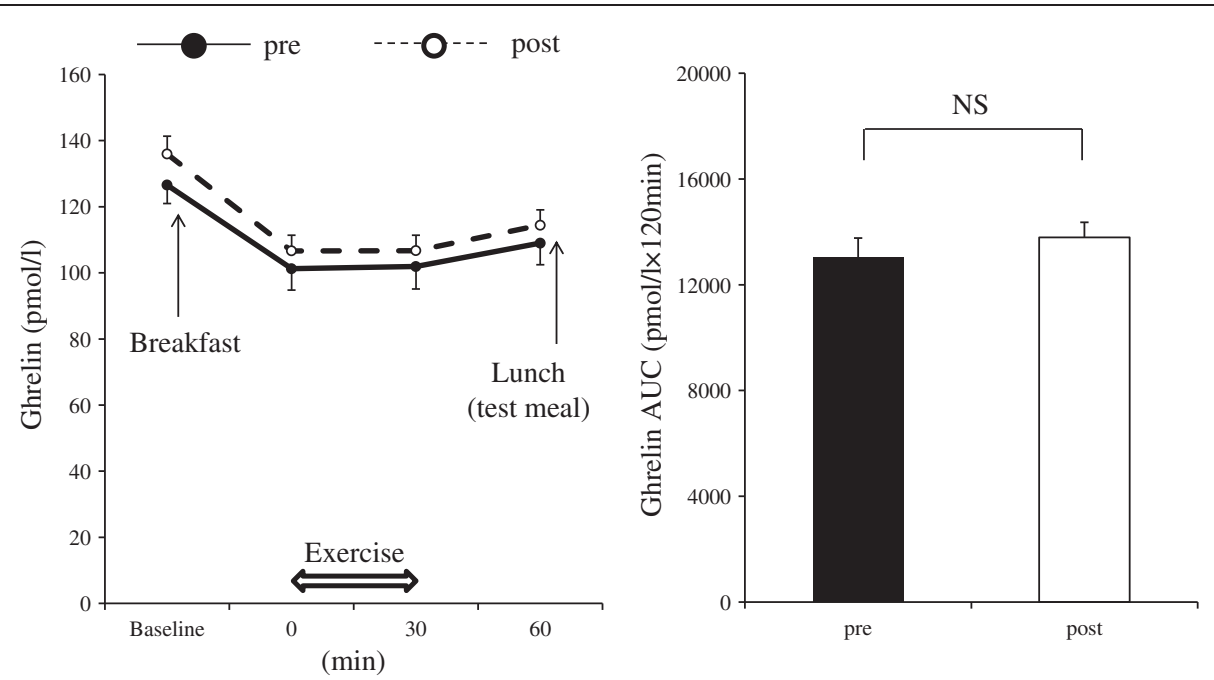

Figure 4 Plasma level responses of ghrelin to a single bout of exercise (left) and area under the curve values for ghrelin (right). Mean values \pm SEM of each parameter are presented. Two-way ANOVA for repeated measures (left): Main effect of exercise training, $P=0.23$; main effect of time, $P<0.001$; interaction effect of exercise training $\times$ time, $P=0.97$.

$\left(\mathrm{r}^{2}=0.535, P<0.01\right)$ were selected as predictive variables of AUC values for GLP-1 levels.

\section{Discussion}

The objective of the present study was to investigate the effects of 12 weeks of exercise training on gut hormone levels after a single bout of exercise in middle-aged Japanese women and to determine whether any changes correlated with the magnitude of exercise traininginduced changes in body composition, fitness levels, and energy intake after the single bout of exercise. The following findings were obtained: 1) Exercise training resulted in a significant increase in acylated ghrelin fasting levels, with no significant changes in GLP-1 or PYY fasting levels. 2) A significant increase in GLP-1

Table 3 Correlations between incremental GLP-1 responses and changes in each measurement parameter

\begin{tabular}{lll}
\hline & $\mathbf{r}$ & $\boldsymbol{P}$ \\
\hline$\Delta$ Weight $(\mathrm{kg})$ & -0.743 & $<0.001$ \\
$\Delta$ Body mass index $\left(\mathrm{kg} / \mathrm{m}^{2}\right)$ & -0.732 & $<0.001$ \\
$\Delta$ Body fat $(\%)$ & -0.731 & $<0.001$ \\
$\Delta$ Peak $\mathrm{VO}_{2}(\mathrm{ml} / \mathrm{kg} / \mathrm{min})$ & 0.558 & $<0.05$ \\
$\Delta$ Energy intake after & -0.649 & $<0.01$ \\
the single bout of exercise $(\mathrm{kcal})$ & & \\
$\Delta$ Fasting glucose $(\mathrm{mg} / \mathrm{dl})$ & -0.214 & $\mathrm{NS}$ \\
$\Delta$ Glucose AUC $(\mathrm{mg} / \mathrm{dl})$ & -0.229 & $\mathrm{NS}$ \\
$\Delta$ Fasting insulin $(\mu \mathrm{U} / \mathrm{ml})$ & -0.337 & $\mathrm{NS}$ \\
$\Delta$ Insulin AUC $(\mu \mathrm{U} / \mathrm{ml})$ & -0.301 & $\mathrm{NS}$ \\
\hline
\end{tabular}

levels and a tendency toward an increase in PYY levels after the single bout of exercise were observed after exercise training. 3) Changes in (delta) GLP-1 AUC were significantly correlated with decreases in body weight, BMI, percent body fat, and energy intake after the single bout of exercise and increases in peak $\mathrm{VO}_{2}$.

Recent studies have begun to shed light on the previously unknown roles of a single bout of exercise in energy intake or appetite regulation through gut hormone release (Broom et al. 2009; Cheng et al. 2009; Martins et al. 2007; Ueda et al. 2009a, b). For the development of new programs for the prevention and treatment of obesity, it is more important to examine whether exercise training also has an impact on the circulating levels of gut hormones and energy intake control as well as a single bout of exercise. In one study, a 12-week supervised exercise training program (five times per week, 75\% maximal heart rate) resulted in a significant reduction in body weight and increase in fasting acylated ghrelin levels, with no significant changes in fasting GLP-1 and PYY levels (Martins et al. 2010). Our findings suggest that exercise training resulted in a significant increase in acylated ghrelin fasting levels and no significant changes in GLP-1 and PYY fasting levels in middle-aged Japanese women, consistent with data from a previous study (Table 2). On the other hand, it has been reported that an 8-month supervised aerobic training program decreased percent body fat and raised fasting PYY levels (Jones et al. 2009). Roth et al. (2005) observed a significant increase in fasting PYY levels in obese children who were successful in losing weight after a 1-year diet and exercise training. In addition, changes in fasting ghrelin levels by 
exercise training were not consistent across these studies (Foster-Schubert et al. 2005; Jones et al. 2009; Kelishadi et al. 2008; Kim et al. 2008; Konopko-Zubrzycka et al. 2009; Leidy et al. 2004; Mackelvie et al. 2007; Martins et al. 2010; Mizia-stec et al. 2008; Morpurgo et al. 2003; Santosa et al. 2007). However, most studies showed a compensatory increase in fasting ghrelin levels in response to reductions in body weight (Foster-Schubert et al. 2005; Kelishadi et al. 2008; Kim et al. 2008; Konopko-Zubrzycka et al. 2009; Leidy et al. 2004; Martins et al. 2010; Mizia-stec et al. 2008; Santosa et al. 2007). For example, whereas total ghrelin fasting levels were not affected by aerobic exercise training for 5 days without reductions in body weight (Mackelvie et al. 2007), fasting plasma levels gradually increased during 12 weeks of aerobic and resistance exercise with significant decreases in body weight and fat; and such reductions were strongly associated with increased fasting ghrelin levels (Kim et al. 2008; Leidy et al. 2004). For longer term exercise training where weight reductions were achieved over one year without caloric restriction, fasting ghrelin levels increased with weight loss, again suggesting a role for ghrelin in the adaptive response constraining weight loss (Foster-Schubert et al. 2005). Such discrepancies may stem from the fact that exercise training-induced changes in fasting levels of total ghrelin, acylated ghrelin, and PYY depended not only on the duration or intensity of the exercise but also on dietary conditions.

In two elegant studies by Donnelly et al. (2003) and Potteiger et al. (2003), 16-month of supervised exercise training by young women did not lead to changes in body weight. However, our findings suggest that a 12week exercise training (three times per week) resulted in a significant decrease in body weight and percent body fat in middle-aged Japanese women (Table 1). Although we cannot provide a definite explanation for such a difference, inconsistent results were due to ethnic differences. Previous studies that have examined the association between the tryptophan-to-arginine (Trp64Arg) variant of the $\beta 3$-adrenergic receptor gene and the magnitude of weight loss achieved by exercise intervention have yielded inconsistent results (Fumeron et al. 1996; Kogure et al. 1998; Rawson et al. 2002; Sakane et al. 1997; Shiwaku et al. 2003; Tchernof et al. 2000; Yoshida et al. 1995). All of the positive results have been reported from Japan (Kogure et al. 1998; Sakane et al. 1997; Shiwaku et al. 2003; Yoshida et al. 1995); and null results were reported from France (Fumeron et al. 1996) and the United States (Rawson et al. 2002; Tchernof et al. 2000), suggesting that the inconsistent results were due to ethnic differences. However, to the best of our knowledge, there are no studies dealing with this topic; thus our hypothesis remains speculative.
Martins et al. (2010) observed a tendency for higher postprandial GLP-1 and PYY levels in overweight/obese men and women after 12 weeks of exercise training. Kelly et al. (2009) reported that an increased PYY response to glucose ingestion was shown in older obese insulin-resistant adults after 12 weeks of exercise training and Chanoine et al. (2008) observed that an acute GLP-1 response to a liquid meal was shown to be enhanced by a 5 -day aerobic exercise training program in normal weight and overweight adolescents. Similarly, our present findings first demonstrated that a significant increase in GLP-1 levels and a tendency toward an increase in PYY levels after the single bout of exercise were observed after 12 weeks of exercise training (Figures 2, 3). These results are likely to be important for developing new exercise programs for the prevention and treatment of obesity. However, because the physiological mechanisms underlying these changes in response to a stimulus have not yet been fully understood, further investigation is warranted. Additionally, we also should have included an experiment without acute exercise to elucidate the pure effect of exercise training on the gut hormone response to the breakfast intake. This could provide a better understanding of the interactions between energy intake, acute exercise, and exercise training on the secretion of gut hormones.

Another important outcome of this study was the fact that increases in AUC values for GLP-1 levels were significantly correlated with decreases in body weight, BMI, percent body fat, and energy intake after the single bout exercise and increases in peak $\mathrm{VO}_{2}$ (Table 3). Previously, we reported that reductions in energy intake after the single bout of exercise were significantly and negatively associated with total increases in GLP-1 concentrations during the single bout of exercise (Ueda et al. 2009a). In this study setting, significant increases in GLP-1 levels after the single bout of exercise were preceded by 12 weeks of exercise training. In other words, these results suggested that the ability of exercise training to create a negative energy balance relies not only directly on its impact on energy expenditure, but also indirectly on its potential to modulate energy intake.

There were some potential limitations to the present study. First, we did not calculate the energy expenditure during whole time course from breakfast until lunch time in each session, but simply expressed as amount of energy ingested at lunch. In the present study, we focused on how much energy subjects consumed at lunch after a single bout of exercise. If we can calculate relative energy intake, results can be used to further understand the interactions between energy balance and exercise training on the secretion of gut hormones. In a future study, we intend to calculate relative energy intake 
Second, we designed the present study, including the timing of energy intake and time of the single bout of exercise, based on our previous paper (Ueda et al. 2009a). Therefore, because the rather unusual eating pattern with only 2 hours between substantial meals may have had effects on the results of this study, it cannot be applied directly to general meal patterns. Further studies are required on the timing of energy intake and the single bout of exercise on gut hormones such as GLP-1, PYY, and ghrelin. Additionally, we cannot rule out the possibility that cognitive or environmental factors affected our findings, although we attempted to carefully exclude such confounding variables by the choice of study design. When allowed to eat ad libitum, obese subjects consumed more food items than subjects with a normal weight (Wing et al. 1978). In fact, in previous studies of appetite in the obese, subjects were instructed to eat ad libitum (Martins et al. 2007, 2010). However, under these circumstances, food intake can be biased by cognitive factors such as the belief that 'food is a reward for exercise' (King 1999). In the present study, a common test meal of noodles was therefore prepared so that subjects would be unaware of food intake during the test (Ueda et al. 2009a, b). In addition, prior to the study, we confirmed that the test meal was palatable to all participants. Third, in the present study, to evaluate gut hormones and energy intake after a single bout of exercise, subjects performed ergometer cycling before and after the exercise training. The intensity of the single bout of exercise was then adjusted to $50 \%$ peak $\mathrm{VO}_{2}$ (same relative intensity). Therefore, although mean $\%$ peak $\mathrm{VO}_{2}$ and heart rate during the single bout of exercise was not different between pre and post exercise training, mean workload post exercise training during the single bout of exercise was significantly higher than that of pre exercise training $(P<0.001$, from $43.5 \pm 0.9$ to $48.1 \pm 0.8 \mathrm{~W})$. Additionally, to identify a true exercise training effect, it will be necessary to match the workload between pre and post exercise training sessions.

In conclusion, our findings showed that, in middleaged Japanese women, GLP-1 and PYY levels after the single bout of exercise were increased by exercise training. In addition, increases in GLP-1 levels were significantly correlated with decreases in body weight, BMI, percent body fat, and energy intake after the single exercise bout and increases in peak $\mathrm{VO}_{2}$. These results suggested that the ability of exercise training to create a negative energy balance relies not only directly on its impact on energy expenditure, but also indirectly on its potential to modulate energy intake. A better understanding of the role of exercise training in energy intake regulation may lead to a more effective prescription of exercise training for weight control.

\section{Competing interests}

All authors declare that they have no competing interests.

\section{Authors' contributions}

SU participated in the critical conception and design, the acquisition of data, analysis and interpretation of data, drafting of the manuscript, and critical revision of the manuscript, and approved the final version. TM, HN, TS, TU, YK, TY, and SF participated in the acquisition of data and approved the final version.

\section{Acknowledgements}

The authors thank all volunteers for their participation in the present study.

\section{Author details}

${ }^{1}$ Department of Acupuncture, Morinomiya University of Medical Sciences, 1-26-16, Nankokita, Suminoe-ku, Osaka City, Osaka 559-8611, Japan.

'Laboratory of Research Promotion and Management, National Cerebral and Cardiovascular Center Research Institute, 5-7-1, Fujishirodai, Suita, Osaka 565-8565, Japan. ${ }^{3}$ Department of Elementary and Preschool Education, Osaka Seikei College, 3-10-62, Aikawa, Higashiyodogawa-ku, Osaka City, Osaka 533-0007, Japan. ${ }^{4}$ Department of Health and Physical Education, Kogakuin University, 2665-1, Nakano-machi, Hachioji City, Tokyo 192-0015, Japan. ${ }^{5}$ Department of Sports Medicine, Osaka City University Graduate School of Medicine, 1-4-3, Asahi-machi, Abeno-kuOsaka City, Osaka 545-8585, Japan.

Received: 25 December 2012 Accepted: 25 February 2013

Published: 5 March 2013

\section{References}

Barrera JG, Sandoval DA, D'Alessio DA, Seeley RJ (2011) GLP-1 and energy balance: an integrated model of short-term and long-term control. Nat Rev Endocrinol 7:507-516

Borg GA (1973) Perceived exertion: a note on "history" and methods. Med Sci Sports 5:90-93

Broom DR, Batterham RL, King JA, Stensel DJ (2009) Influence of resistance and aerobic exercise on hunger, circulating levels of acylated ghrelin, and peptide $Y Y$ in healthy males. Am J Physiol Regul Integr Comp Physiol 296:R29-R35

Chanoine JP, Mackelvie KJ, Barr SI, Wong AC, Meneilly GS, Elahi DH (2008) GLP-1 and appetite responses to a meal in lean and overweight adolescents following exercise. Obesity (Silver Spring) 16:202-204

Cheng MH, Bushnell D, Cannon DT, Kern M (2009) Appetite regulation via exercise prior or subsequent to high-fat meal consumption. Appetite 52:193-198

Derosa G, Maffioli P (2012) Anti-obesity drugs: a review about their effects and their safety. Expert Opin Drug Saf 11:459-471

Donnelly JE, Kirk EP, Jacobsen DJ, Hill JO, Sullivan DK, Johnson SL (2003) Effects of 16 mo of verified, supervised aerobic exercise on macronutrient intake in overweight men and women: the Midwest Exercise Trial. Am J Clin Nutr 78:950-956

Field BC, Chaudhri OB, Bloom SR (2009) Obesity treatment: novel peripheral targets. Br J Clin Pharmacol 68:830-843

Flint A, Raben A, Blundell JE, Astrup A (2000) Reproducibility, power and validity of visual analogue scales in assessment of appetite sensations in single test meal studies. Int J Obes Relat Metab Disord 24:38-48

Foster-Schubert KE, McTiernan A, Frayo RS, Schwartz RS, Rajan KB, Yasui Y, Tworoger SS, Cummings DE (2005) Human plasma ghrelin levels increase during a one-year exercise program. J Clin Endocrinol Metab 90:820-825

Fumeron F, Durack-Bown I, Betoulle D, Cassard-Doulcier AM, Tuzet S, Bouillaud F, Melchior JC, Ricquier D, Apfelbaum M (1996) Polymorphisms of uncoupling protein $(U C P)$ and beta 3 adrenoreceptor genes in obese people submitted to a low calorie diet. Int J Obes Relat Metab Disord 20:1051-1054

Gallwitz B (2012) Anorexigenic effects of GLP-1 and its analogues. Handb Exp Pharmacol 209:185-207

Jones TE, Basilio JL, Brophy PM, McCammon MR, Hickner RC (2009) Long-term exercise training in overweight adolescents improves plasma peptide $Y Y$ and resistin. Obesity (Silver Spring) 17:1189-1195

Karra E, Batterham RL (2010) The role of gut hormones in the regulation of body weight and energy homeostasis. Mol Cell Endocrinol 316:120-128

Kelishadi R, Hashemipour M, Mohammadifard N, Alikhassy H, Adeli K (2008) Short- and long-term relationships of serum ghrelin with changes in body 
composition and the metabolic syndrome in prepubescent obese children following two different weight loss programmes. Clin Endocrinol (Oxf) 69:721-729

Kelly KR, Brooks LM, Solomon TP, Kashyap SR, O'Leary VB, Kirwan JP (2009) The glucose-dependent insulinotropic polypeptide and glucose-stimulated insulin response to exercise training and diet in obesity. Am J Physiol Endocrinol Metab 296:E1269-E1274

Kim HJ, Lee S, Kim TW, Kim HH, Jeon TY, Yoon YS, Oh SW, Kwak H, Lee JG (2008) Effects of exercise-induced weight loss on acylated and unacylated ghrelin in overweight children. Clin Endocrinol (Oxf) 68:416-422

King NA (1999) What processes are involved in the appetite response to moderate increases in exercise-induced energy expenditure? Proc Nutr Soc 58:107-113

Kogure A, Yoshida T, Sakane N, Umekawa T, Takakura Y, Kondo M (1998) Synergic effect of polymorphisms in uncoupling protein 1 and beta3-adrenergic receptor genes on weight loss in obese Japanese. Diabetologia 41:1399

Konopko-Zubrzycka M, Baniukiewicz A, Wróblewski E, Kowalska I, Zarzycki W, Górska M, Dabrowski A (2009) The effect of intragastric balloon on plasma ghrelin, leptin, and adiponectin levels in patients with morbid obesity. J Clin Endocrinol Metab 94:1644-1649

Leidy HJ, Gardner JK, Frye BR, Snook ML, Schuchert MK, Richard EL, Williams NI (2004) Circulating ghrelin is sensitive to changes in body weight during a diet and exercise program in normal-weight young women. J Clin Endocrinol Metab 89:2659-2664

Mackelvie KJ, Meneilly GS, Elahi D, Wong AC, Barr SI, Chanoine JP (2007) Regulation of appetite in lean and obese adolescents after exercise: role of acylated and desacyl ghrelin. J Clin Endocrinol Metab 92:648-654

Martins C, Morgan LM, Bloom SR, Robertson MD (2007) Effects of exercise on gut peptides, energy intake and appetite. J Endocrinol 193:251-258

Martins C, Kulseng B, King NA, Holst JJ, Blundell JE (2010) The effects of exerciseinduced weight loss on appetite-related peptides and motivation to eat. J Clin Endocrinol Metab 95:1609-1616

Mizia-Stec K, Zahorska-Markiewicz B, Olszanecka-Glinianowicz M, Janowska J, Mucha Z, Holecki M, Gasiora Z (2008) Ghrelin as a potential blood pressure reducing factor in obese women during weight loss treatment. Endokrynol Pol 59:207-211

Morpurgo PS, Resnik M, Agosti F, Cappiello V, Sartorio A, Spada A (2003) Ghrelin secretion in severely obese subjects before and after a 3-week integrated body mass reduction program. J Endocrinol Invest 26:723-727

Neary MT, Batterham RL (2009) Gut hormones: implications for the treatment of obesity. Pharmacol Ther 124:44-56

Nguyen AD, Herzog H, Sainsbury A (2011) Neuropeptide Y and peptide YY: important regulators of energy metabolism. Curr Opin Endocrinol Diabetes Obes 18:56-60

Potteiger JA, Jacobsen DJ, Donnelly JE, Hill JO (2003) Midwest Exercise Trial. Glucose and insulin responses following 16 months of exercise training in overweight adults: the Midwest Exercise Trial. Metabolism 52:1175-1181

Rawson ES, Nolan A, Silver K, Shuldiner AR, Poehlman ET (2002) No effect of the Trp64Arg beta(3)-adrenoceptor gene variant on weight loss, body composition, or energy expenditure in obese, caucasian postmenopausal women. Metabolism 51:801-805

Roth CL, Enriori PJ, Harz K, Woelfle J, Cowley MA, Reinehr T (2005) Peptide YY is a regulator of energy homeostasis in obese children before and after weight loss. J Clin Endocrinol Metab 90:6386-6391

Sakane N, Yoshida T, Umekawa T, Kogure A, Takakura Y, Kondo M (1997) Effects of Trp64Arg mutation in the beta 3-adrenergic receptor gene on weight loss, body fat distribution, glycemic control, and insulin resistance in obese type 2 diabetic patients. Diabetes Care 20:1887-1890

Santosa S, Demonty I, Lichtenstein AH, Cianflone K, Jones PJ (2007) An investigation of hormone and lipid associations after weight loss in women. J Am Coll Nutr 26:250-258

Schellekens H, Finger BC, Dinan TG, Cryan JF (2012) Ghrelin signalling and obesity: At the interface of stress, mood and food reward. Pharmacol Ther 135:316-326

Shiwaku K, Nogi A, Anuurad E, Kitajima K, Enkhmaa B, Shimono K, Yamane Y (2003) Difficulty in losing weight by behavioral intervention for women with Trp64Arg polymorphism of the beta3-adrenergic receptor gene. Int J Obes Relat Metab Disord 27:1028-1036

Tchernof A, Starling RD, Turner A, Shuldiner AR, Walston JD, Silver K, Poehlman ET (2000) Impaired capacity to lose visceral adipose tissue during weight reduction in obese postmenopausal women with the Trp64Arg beta3adrenoceptor gene variant. Diabetes 49:1709-1713
Torekov SS, Madsbad S, Holst JJ (2011) Obesity - an indication for GLP-1 treatment? Obesity pathophysiology and GLP-1 treatment potential. Obes Rev 12:593-601

Ueda SY, Yoshikawa T, Katsura Y, Usui T, Fujimoto S (2009a) Comparable effects of moderate intensity exercise on changes in anorectic gut hormone levels and energy intake to high intensity exercise. J Endocrinol 203:357-364

Ueda SY, Yoshikawa T, Katsura Y, Usui T, Nakao H, Fujimoto S (2009b) Changes in gut hormone levels and negative energy balance during aerobic exercise in obese young males. J Endocrinol 201:151-159

Ueno H, Yamaguchi H, Mizuta M, Nakazato M (2008) The role of PYY in feeding regulation. Regul Pept 145:12-16

Wing RR, Carrol C, Jeffrey RW (1978) Repeated observation of obese and normal subjects eating in the natural environment. Addict Behav 3:191-196

Yoshida T, Sakane N, Umekawa T, Sakai M, Takahashi T, Kondo M (1995) Mutation of beta 3-adrenergic-receptor gene and response to treatment of obesity. Lancet 346:1433-1434

doi:10.1186/2193-1801-2-83

Cite this article as: Ueda et al:: Effects of exercise training on gut hormone levels after a single bout of exercise in middle-aged Japanese women. SpringerPlus 2013 2:83.

\section{Submit your manuscript to a SpringerOpen ${ }^{\circ}$ journal and benefit from:}

- Convenient online submission

Rigorous peer review

- Immediate publication on acceptance

- Open access: articles freely available online

- High visibility within the field

- Retaining the copyright to your article

Submit your next manuscript at springeropen.com 